\title{
The Proximate Pleasure of Eve Sedgwick: A Legacy of Intimate Reading ${ }^{1}$
}

\section{ELIZABETH MCMAHON}

They're all the same, these tricksters; they have no shame and so have no silence. (Hyde 153)

In her introduction to Novel Gazing Sedgwick writes that 'pleasure, grief, excitement, boredom, satisfaction are the substance of politics rather than their antithesis'. Further, she advises that we attend 'intimately to literary texts' because their 'transformative energies' are 'the stuff of ordinary being' (1). This essay speculates on the ways Sedgwick remapped the relationship between affect, intimacy and politics as a queer critical practice. It will consider the dynamism of this relationship in terms of the new spatialities of reading it enables, focusing on the operations of juxtaposition and proximity that her writing enacts. This focus is motivated by the understanding that Sedgwick deploys juxtaposition and proximity as strategies to confound accepted decorum regarding appropriate associations between subjects and objects, including the relationship between herself as author, the subject matter of her inquiry, and the reader. Further, her continuous re-assemblage of relations serves to remind us of the contingent or arbitrary nature of classificatory practices themselves. This essay argues that Sedgwick's complex re-negotiation of relations comprises one of her most radical and enduring analytical praxes. For the reader is invited to enter into the processes of contingent thought and analysis in a temporality of the present, a shared moment of thought and affect that is itself necessarily creative.

Sedgwick's remapping of relations, including the destabilization of the authorsubject, is akin to Donna Haraway's formulation of 'situated knowledges', first published in 1988, and in expanded form in 1991 - ie, at around the same time as Sedgwick's Between Men (1985) and Epistemology of the Closet (1991). In her famous essay Haraway argues for

\footnotetext{
1 Ken Gelder deploys the term 'proximate' in a related sense in his essay 'Proximate Reading: Australian Literature in Transnational Frameworks', forthcoming in JASAL 2010. Gelder uses the term to conceptualise new relations between readers, texts and meaning in transnational modernity.

This essay is indebted to the work of Elizabeth A Wilson. Her extensive analysis of affect is forthcoming in Affect and artificial intelligence (Seattle: University of Washington Press, 2010). I would also like to acknowledge and thank Monique Rooney for her detailed and astute editorial work on this essay.
} 
politics and epistemologies of location, positioning, and situating, where partiality and not universality is the condition of being heard to make rational knowledge claims. These are claims on people's lives. (589)

Like Sedgwick, Haraway dismisses the idea of impartial objectivity as an illusion, whether motivated by positivist or transcendental perspectives. Both Sedgwick and Haraway stress that the viewing position of the inquirer is situated, political and partial and that the putative object of inquiry, conventionally understood as free-standing, is but one aspect or moment in these relations. Further, both call for the agonistic rehearsal of the terms of these relations as part of critical methodology.

The projects of these two important theorists are, of course, separated by the particular fields of study and also by what I call Sedgwick's politics of tone, by which I mean the manner in which she situates herself, and the implications of this process for the reader, which is inseparable from the gesture itself. Thomas S. Frentz's recent essay on Haraway suggests the ways in which Haraway's feminist vision might well be enhanced by 'laughter, vulnerable feelings, and a narrative form of lived experience' (841), which he associates with the figure of the trickster. Frentz's model of radicality picks up on Haraway's own invocation of the trickster figure from Southwest native American accounts, which she posits as a model of productive disruption (Haraway 593). Whatever one makes of Frentz's desire to transform Haraway, his description accurately describes Sedgwick as trickster. 'Laughter' and 'vulnerable feelings', together with the 'narrative form of lived experience', are lynchpins of Sedgwick's approach. Indeed it is the particular, complex and affective relationality between text, author and reader she constructs - what in literary criticism is conventionally understood as tone - that is one of the enduring legacies of Sedgwick's work and constitutes a formal enactment of her critical project.

Tricksters also reconstitute and reform these relations, George Kamberelis argues. They do this by embodying

the human capacity to (a) engage in abductive practices (bricolage) that bring forth new modes of being and acting from not-yet-articulated possibilities and (b) create abductive texts (montage, pentimento, and pastiche) that disrupt culturally contrived/inscribed boundaries. (Kamberelis 678, qtd in Frentz 822)

By these means, Kamberelis claims, the trickster excites others to thought and action (Frentz 822). This is true of Sedgwick's performative analysis, which opened up such possibilities for her readers and queer culture more broadly. This essay claims further that this spur to thought and action is embedded in the tone of her writing, which includes the reader in the process of its own thought 
and action. In the texts I focus on here-Epistemology of the Closet, Tendencies (1993), the Introductions to Novel Gazing and Shame and her Sisters (1997 and 1995) - her invitation to this intimate reading practice was taken up by many and inspired many imitators. Indeed critics, such as Marilee Lindemann, have argued that queer analytical practice may have privileged the pleasure of this constitutive capacity, its ability to form a dynamic subjectivity and community, at the expense of other forms of political action. Thus, at this juncture, not long after her death, it is necessary to examine the embodied intimacy of Sedgwick's own writing: its contradictory capacity to identify and generate difference. For it may be that it is precisely this generosity and tutelage of her writing that threatens to distance her from us and consign her to the precise historical terms of these relations. This essay seeks to identify a number of the ways the invitation to engagement is issued in her writing through the overlaid patterns of relationality, and calibrate the efficacy of her method for ongoing inquiry. In this process, I situate Sedgwick as a trickster, a figure which may, ironically, locate her originality. For its association with a recognized tradition or tropism places it in a continuum into the future.

To follow Sedgwick herself, we could say the relational is axiomatic to her work. Hers is a relational analytic, affect, aesthetic and politics, hence the titles Between Men (1985), Tendencies (1993), A Dialogue on Love (1999), and her definition of the 'immemorial current' of queer in the Foreword to Tendencies: 'Keenly, it is relational, and strange' (xii). Her project is to identify and re-imagine relations across and between subjects, objects, discourses, institutions, readers and texts, ${ }^{2}$ as she and Adam Frank state explicitly in the Introduction to Shame and her Sisters:

The bipolar transitive relations of subject to object, self to other, active to passive and the physical sense (sight) understood to correspond most closely with these relations are dominant organising tropes to the extent that their dismantling as such is framed as both an urgent and interminable task. (1)

To this end Sedgwick deploys a range of rhetorical manoeuvres by which she alters accepted relations and, while each of these moves has distinct properties, it is in some ways inseparable from the rest, constructing alignments and misalignments that overturn convention. One characteristic move prises apart naturalised connections founded on a priori assumptions and complicit

2 As Stephen L. Barber and David L. Clark put it, Sedgwick's work changed for a generation of scholars and activists 'how we think about the nexus of identities, desires, bodies, prohibitions, discourses and the play of power' (3; italics mine). 
ideologies to reveal not only the perfidy but the stagnation and tedium of their alignment. And so, for instance, in the 'Queer and Now' chapter of Tendencies she writes of 'Christmas effects':

What's queer? Here's one train of thought about it. The depressing thing about the Christmas season - isn't it - is that it's the time when all the institutions are speaking with one voice. The Church says what the Church says. But the State says the same thing: maybe not (in some ways it hardly matters) in the language of theology, but in the language the State talks: legal holidays, long school hiatus, special postage stamps, and all. And the language of commerce chimes in, as consumer purchasing is organized more narrowly around the final weeks of the calendar year, the Dow Jones aquiver over Americans' holiday mood.

\section{$[\ldots]$}

They all-religion, state, capital, ideology, domesticity, the discourse of power and legitimacy-line up so neatly with each other once a year, and the monolith so created is a thing one can come to view with unhappy eyes. (5-6)

There are two gendered figures by which she hypostatizes ideological uniformity here: the phallicised obdurance of the monolith, an image of congratulatory self-agreement and assumed prerogative, self-aurifying, congealed and lumpen; and a kind of Stepford Wives model of mindless replication and consumption. In the stead of these two models of sameness, Sedgwick proposes a practice of valuing the ways in which meanings, institutions and the elements of individual subjectivity can be at 'loose ends with each other'. She aims to disarticulate and disengage the 'lockstep of unanimity' in monolithic systems and institutions (6).

She deploys this same deconstructive optic to identify and challenge naturalised self-alignments in her own and others' academic methodologies, those implicit alignments by which academic inquiry unwittingly falls in with monological structures even when speaking against them. In her essay 'Nationalisms and Sexualities: As opposed to What?' she animadverts on a conference held at her own institution and in which she participated concerning Liberal Arts Education in the late twentieth century. While the conference included a range of contestatory topics and a diversity of approaches - seemingly a model of an environment at 'loose ends with each other' - Sedgwick's reflections on the conference at its conclusion identify a naturalised unanimity in the shared implicit acceptance of the relationship between liberal arts and the shoring up of the 'nation'. While the explicit topic of each paper or panel may have destabilized accepted understandings in different discourses, there was, for Sedgwick, a stable presumption on the 'primary realness of - of all imaginary 
things in the world-America' (Tendencies 144). For Sedgwick, nationalism or the idea of 'America' that was unconsciously at work throughout the conference, holding it together, in some ways perpetuated the 'lockstep of unanimity' of liberal arts education with nationalism.

That the conference attracted criticism from conservative sections of the media and academy for fostering a decentred conception of literature only underscores her point. The target of the criticism is that the event's emphasis on the theories and practices of diversity constitutes an abjuration from the responsibility of the liberal arts to mold proper national subjects. In this claim, the criticism picks up on the unstated alignment between liberal arts education and nationalism at work in the conference itself. Further, the criticism is a clear enactment of the fear that diversity and dissent in one half of this reflexive couple (the liberal arts) will necessarily instill difference and dissent in the other (the nation). In a typical move, Sedgwick then proceeds from the lesson gleaned by this experience to perform a literary-theoretical reading in which she draws the threads of nationalist ideology at work in the already complex construction of sexuality, subjectivity and literature she examined in earlier works.

The performance of her analytical praxis as a series of graduated stages and revisions in 'Nationalisms and Sexualities' shows how the complication of naturalised alignments is as much about bringing together as it about prising apart. For her, the act of making explicit the nationalist agenda of the liberal arts simultaneously recognises and examines their inter-relation while seeking to fracture their homologous affiliation. The pattern of Sedgwick's argumentation is paradoxical in that distance and difference are enabled by the identification of, and immersion in, the intractability of unspoken connection. Accordingly, Sedgwick's practice of bringing together the seemingly incongruous, the disallowed and the denied into a myriad of dynamic associations can be seen as another move within the same operation. But where she wrenches apart the components of an accepted unanimity, her process of establishing incongruous or improper connections challenges the naturalised borders of proper separation.

In this vein she employs the proximity of juxtaposition and oxymoron for their conventional capacities to shock. The title of her famous essay 'Jane Austen and the Masturbating Girl', for instance, derives its enduring humour from its breach of the tacit proprieties concerning the metonymic operation of Jane Austen as a literary safe haven for girls. In certain of its canonical readings - and this may be a broader function of canonicity itself-Austen's fiction is located outside or before the discursive deployment of sexuality; that is, in an imagined temporality before female sexuality itself. As Sedgwick notes, texts about female sexuality 'are supposed not to have had a broad discursive circulation until 
later in the nineteenth century' (Tendencies 114). Hence Austen, her novels and readers are easily imagined in a place outside or before sexuality itself, a view that is underpinned by the fetishisation of Austen as a virgin spinster.

So, too, the essay's title and its substance write against the avowed heteroerotic program of romance narratives and their overdetermined imperative to coupled conclusion. Sedgwick's reading of Sense and Sensibility complicates this certainty to locate the function of heteroerotics within a broader circulation in which alloerotic and autoerotic relations represent intimacy and interiority. She does not designate one sexuality to replace another but proposes a queer reading in which sexuality is in process and constructed by forms of sociality and by genre. Further, this circulation is enmeshed in the fantastical practices of reading and writing. In these connected ways, Sedgwick juxtaposes her own close reading of Austen, not only with dominant scholarship on the canonical author that ascribes a lack of female agency to her heroines, but also with readings of her work that are framed by an overly prescriptive, historical consciousness. She brings Austen close to us not by diminishing her historical distance but by traversing the distance of Austen's auratic canonicity, that presumes the text is already known. Her close reading of Austen exposes its place, in literary history, as one that comes before the advent of modern female sexuality yet is engaged in its formation. Sedgwick's close reading thus breaches the distance between contemporary critic and auratic, scholarly text, and in doing so, elicits our intimate attention.

It is precisely this proximity that accounts for the vehement responses of the many commentators for whom the title represented a form of academic degeneracy. Sedgwick writes that the essay title was adopted by journalists as 'an index of depravity in the academy' and that it 'lets absolutely anyone, in the righteously exciting vicinity of the masturbating girl, feel a very pundit' (Tendencies 109; italics mine). Here Sedgwick exposes one of the calculated but costly risks of her approach. For, as she argues, the detractors may locate their judgments at a distance from her own, but their very locatedness is enabled by the range of new relations of her intimate reading practice.

The chapter 'Wilde, Nietzsche, and the Sentimental Relations of the Male Body' in Epistemology of the Closet also assembles ostensibly disparate components and shows the efficacy of their connection. Here, Sedgwick brings together Wilde, Nietzsche, and Willie Nelson, but also contemporary politics and literary classics, pedagogy and literary analysis, high culture and popular culture. Moreover, as with the opening narrative of the university conference in 'Nationalisms and Sexualities', the assembled subjects of discussion are linked by their significance to the authorial subject: an academic in nineteenth-century literary studies and queer studies; but also a car driver who listens to 'shit-kicker' radio and responds on cue to the emotional reaches of country music. The essay is 
thus performative in that the movement across the disparate components and registers of the author's subjectivity mirrors the topic of discussion, namely the circulation of sentimentality as a marker of homosexuality.

This circulation is rendered problematic by Sedgwick's location in this economy; her access to male homosexual desire and representation is enabled in this essay by her capacity to share in the sentimental relations between men that does and does not codify homosexuality. Of course one of the most startling aspects of the Willie Nelson story to the new reader of Sedgwick is her admission of heterosexual desire, though this is not a simple matter - if it ever was. Anyone who has taught Sedgwick in sexuality courses is familiar with the moment when students first encounter the seeming anomaly that the Queen of Queer Studies was happily married to Hal Sedgwick-for 40 years. This is not an incidental aspect of her relation with her reader. Many of her obituaries presented this information as an interesting disequilibrium, which is not entirely wrong. It is a significant aspect of her positioning as a situated subject and of that subject's currency in a new field of inquiry. Firstly, of course, her position performs the universalising view of the sexuality she sets out on the first page of Epistemology of the Closet by which the homo-heterosexual definition is an issue of 'continuing determinative importance in the lives of people across the spectrum of sexualities'.

She deploys this insight to produce such original literary readings, in which, for instance, the representation of lesbian nuns in Diderot's fiction provides a way to understand the operations of all knowledge (Tendencies 23-51). This universalizing approach is qualified and personalized, however, by her evident interest in the lives and representations of gay men and the circulation of male desire. Sedgwick shifts the formal ground of relationality by the particular relations of her own position within the components that constitute tone: reader, topic or subject matter, and the broader text. As the writer of the text, Sedgwick is explicitly situated, embodied, political and partial. And so in the concluding pages of the 'Axiomatic' in Epistemology of the Closet, she writes of her own vicarious investments in gay fiction:

There may be a rich and conflictual salience of the vicarious embedded within gay fiction. I don't point this out to offer an excuse for the different, openly vicariating cathexis from outside that motivates this study; it either needs or, perhaps, can have none. But this in turn may suggest some ways in which the particular obliquities of my approach to the subject may bias what I find here. (62-63)

There are many such passages in Sedgwick's work, where she draws our attention to what appear to be the limits of her inquiry. However this selflocation and self-implication provides a more precise inflection of reading and 
writing desire at work and invites the reader to position herself. In my own reading of Sedgwick, the instance that most challenged me on first reading in 1991 was her admission to enjoying country and western music and the erotic and sentimental portrayals of men therein. The levels and registers of the incongruous are set out here with such pleasure:

One night in Ithaca in the mid-seventies, I happened to tune into a country music station in the middle of a song I had never heard before. An incredibly pretty male voice that I half recognized as Willie Nelson's was singing:

And he walks with me, and he talks with me,

And he tells me I am his own.

And the joy we share as we tarry there,

None other has ever known.

He speaks; and the sound of his voice Is so sweet the birds hush their singing.

And the melody that he gave to me

Within my heart is ringing.

And he walks with me, and he talks with me,

And he tells me I am his own.

And the joy we share as we tarry there,

None other has ever known.

I'd stay in the garden with him

Though the night around me is falling,

But he bids me go through the voice of woe,

His voice to me is calling.

She comments: 'This blew me away' (142). She records her amazement that erotic relations between men could be played with such candour on 'shitkicker' radio. She peers through the conventions of religious kitsch that provide the alibi for this erotic and sentimental representation and sees the richness of erotic relations and identifications the song offers. She thereby draws our attention to a disavowed homoeroticism at work in mainstream culture. Her recognition of this connection is the work of a trickster: we are accustomed to the connection between religious and erotic discourses, though this connection may still give pause in some quarters. Sedgwick's innovation here is the linking of eroticism with sentimentality and with the signaling of the availability of both to those who do not properly belong to them: a woman, a non-Christian, a ruthlesslyprecise analytic subject. She is a trickster too in that her insight derives not only from her an 'abductive', in this case somatic, response but from the willingness to trust and follow that response. 
The ensuing discussion further complicates this admission. She picks up the story ten years after her experience of radio rapture, when she encounters an essay on religious kitsch that criticises sentimentality and which directly references a version of the hymn Willie Nelson sings. Sedgwick identifies the twofold source of the author's disgust: 'one is topical, concerning the subject of sentimentality; and one grammatical, regarding its relations' (142) The second of these, the relational and grammatical pertains to the discussion at hand. As Sedgwick asserts, the first person 'I' can pertain to either gender, thereby enabling multiple identifications, of which Sedgwick avails herself. Moreover she identifies the equivocal first person or impossible first person (the dead speaker) as a particularly potent sentimental marker. She writes of her own response to this figure:

My goose bumps are always poised for erection at 'She walks these hills in a long black veil,/Visits my grave when the night winds wail.' And my waterworks are always primed for 'Rocky, I've never had to die before.' (143)

Sedgwick herself performs the slippage across gender in her somatic responses: she is both 'poised for erection' and her 'waterworks are always primed'. As if in response to the gendered forms of sameness posed by monolithic alignments Sedgwick occupies and commandeers the prerogative of both sexed responses. Further, her own relation to the sentimental object itself is multiple: she is excited both by the male body as it is foregrounded for her as ' $\mathrm{I}$ ' and by the ways it operates as an erotic object between men, a scene in which she is an onlooker. Furthermore, these positions are not mutually exclusive. Hence she concludes that sentimentality is not so much a thematic of a particular subject matter but a structure of relation.

For a writer as relentlessly analytical as Sedgwick, the absence of any account of her tastes and preferences is very marked in this discussion. Nor does she provide an analysis of tastes and preferences. She re-orders the relationship between subjects and objects by refusing to validate or explain the connections. They just are what they are. This is not to argue that she imagines these as self-generated but that her silence is a presumption of the legitimacy of her predelictions. This refusal to explain taste and preference in regard to her own sentimental and erotic responses is also refusing the need to account for homosexual origin and preference. As she readily acknowledges, her own identity is not subject to the political and cultural opprobrium of homosexual subjects but is tricksterlike. She does use 'vulnerable feelings' in an overdetermined sense here, that is as a stand-in for a shared sentimentality that is the means by which she repositions relations, to perform, in her own terms, a 'universalising' view that is nonetheless a 'situated knowledge'. 
This performance of subjectivity and pleasure is risky for a range of reasons, one of which Marilee Lindemann sets out in her review of Novel Gazing, which opens: 'The first line of this essay was going to be, Queer Studies is fun' (Lindemann 757). Lindemann questions the direction in which she perceives queer studies to be heading because she thinks it is "possible to foresee "queer studies without lesbians and gay men"' (767). She is also concerned that queer studies is not effecting any change in the status of people with 'nonprocreative sexualities' in institutions or the broader culture. Lindemann's reading poses a number of questions for Sedgwick's queer reading practice, especially as it has been taken up by devotees of her work. Most obviously, Lindemann's reservations echo the controversy Judith Butler's performative understanding of gender posed for feminism - namely that the volatile understanding of subjectivity may jeopardise a politics based on identification. Perhaps, also, Lindemann's argument directs us to a problematic of queer studies itself, as practiced by Sedgwick, which is that it might be based on a set of practices that presume a kind of gender separateness. In this latter reading, Lindemann's argument is an inevitable point of critique in the terms of the field itself. Indeed, the style, tone and structure of Lindemann 's essay locate her in this field, even if her essay is thoughtfully posited. The essay is at first entertaining and personal, setting up the project of reviewing as a situated dilemma in time, and then moves to a counter-narrative of queer studies derived from pedagogic experience. The mode and the tone are Sedgwickian. And it is not so much the humour or the pleasure that characterizes the connection but the moves across the registers of academic inquiry and everyday experience. Lindemann is writing in the very space that Sedgwick helped construct. That she arrives at a distinctive position that includes criticism of Novel Gazing only emphasizes this point.

This critique of Sedgwick is useful here too in relation to the questions of shame that preoccupied Sedgwick via Silvan Tomkins. Shame, according to Tomkins, 'is the affect of indignity, of defeat, of transgression, and of alienation' (Shame 133) but it is also an originary affect. Hence Sedgwick and Frank claim that 'for Tomkins not only shame but also theory come from shame theory' (22). In the terms of Stephen Barber and David L. Clark, shame for Sedgwick 'vivifies and consolidates the subject in a moment of wincing isolation' (Barber and Clark 26). In the terms of this essay, shame shores up the subject in the moment of their individual if embarrassed intervention in academic inquiry. In a shame-prone environment such as the academy, Sedgwick's legacy is a model of intellectual inquiry that is relentless, even ruthless, in its attention and precision. Yet, like Tomkins whose 'brash generosity' she so admired, she 'burns out the fear response' of complex argument and disallowed discussion by casting it as a shared present moment of discovery (Shame 1,3). The act of burning out the 
fear response occurs when anticipated rejection and shame are admitted and performed for us and shown to be neither annihilating or conclusive. Crucially, this act is not the eradication of shame but the acceptance of it.

Paradoxically, Sedgwick's acceptance of shame paves the way for unashamed and shameless inquiry, for shame is no longer a brutalizing endpoint. If, as Tomkins argues, shame is affect of strangeness - where one is shamed because our anticipated or sought-after acceptance is turned down-Sedgwick has provided a field of potential recognition and identification (Shame 123). In this way admission, embarrassment and the fear of error lose their deflating power in a circulation of ongoing realization, refinement and pleasure. Part of her gift in such shame-prone environments as the academy and queer communities is her acceptance of shame alongside a facilitating performance of continuing unashamed and shameless.

This refusal of the shameful ending re-situates the relation between writer, text, and reader and constitutes a radical practice that has contagious effects. There is a generosity in Sedgwick's self-placement here - and elsewhere - which is all the more so because it is implicit, embedded in the structures and grammar of her writing. The space she carves out for the relationship between writer and reader is one of co-readership. Reading is a shared enterprise - as evidenced by our reading of her reading. Reading is constructed in this narrative of reading as developing and accumulating over time. In the instance of her discussion of sentimentality, she gives us a narrative of reading according to the progression of Pindaric ode as deployed by the Romantic poets: strophe-antistrophe-epode or thesis-antithesis-synthesis. But here the somatic and sublime experience comes first (hearing Willie Nelson on the radio), followed by a disembodied analysis (not hers in this case) and then the yoking together of these two moments - ten years apart - for the embodied analysis that proceeds.

We, the readers, are allowed into this process as it develops and she presumes we are with her. Just as the hymn brought her into company of the speaker and his desired object who 'walks with me, and [...] talks with $\mathrm{me}^{\prime}$, we are invited to 'tarry' with (the auratic figure of) Sedgwick and re-form the relations of her discussion by our intervention. In this way, too, Sedgwick is a trickster, for she both breaches distance between auratic texts and secular readers yet also reinstitutes a reminder of the distance between star-author and close reader. She lets you in on the jokes, she happily owns her own position, she moves between the vernacular and highly formal academic idiom and in so doing enables and invites an intimate reading practice across difference. As an academic, what she convinces you, in addition to her many insights, is that there is nothing else you would rather do. For there is such pleasure in this activity, including engagement with the arcane and the vernacular, the cognitive and affective, the aesthetic and the political, which, when unashamed, provides, for those 
inclined, those with those tendencies, a radical means by which to position themselves as inquiring subjects. What she restores to us as a kind of birthright is the pleasure of the libidinal charge of thought and writing.

The jury is out as to whether this legacy will continue. We are very familiar with the disequilibrium between the radical topics undertaken by some of the most conservative practitioners of our disciplines. The dominant mode of writing and communication remains staunchly monological, monolithic. It denies the historicity of its own invention in a bid to ensure an ahistorical relevance. Sedgwick's self-positioning must date her for she strenuously engages with chronology: her daily life in teaching and researching, her friends and colleagues, her anecdotes from the classroom, current cultural issues, the ways she shared the euphoria of the 'queer' moment of 1992 (Tendencies). One way of keeping her close, I am suggesting here, is to attend intimately to her texts and enter into their complex relationality. She opened up not only new spaces for inquiry and the inquirer but also the possibility of their ongoing dynamism. Furthermore she 'burned out the fear response' attendant on the necessary risks of this mode in inquiry. It is here, as ironic chameleon or trickster, that she teaches us how to read and, for many of us, how to live a reading, writing life.

Elizabeth McMahon is a senior lecturer in the English program at the University of New South Wales. The former editor of AHR, she now co-edits Southerly, Australia's oldest literary journal. She has published extensively on gender in Australian literature and culture and with Brigitta Olubas edited Women Making Time: Contemporary Feminist Critique and Cultural Analysis (UWA Press 2006) and Remembering Patrick White: Contemporary Critical Essays (Rodopi 2010).

\section{Works Cited}

Barber, Stephen M., and David L. Clark. Regarding Sedgwick: Essays on Queer Culture and Critical Theory. New York: Routledge, 2002.

Frentz ,Thomas S. 'Split Selves and Situated Knowledges: The Trickster goes Titanium.' Qualitative Inquiry 15.5 (2009): 820-842.

Gelder, Ken. 'Proximate Reading Practices: Australian Literature in Transnational Frameworks.' JASAL 2010 (forthcoming).

Haraway, Donna. 'Situated Knowledges: The Science Question in Feminism and the Privilege of Partial Perspectives.' Feminist Studies 14.3 (1988): 575-599. 
Hyde, Lewis. Trickster Makes This World: Mischief, Myth, and Art. New York: Farrar, Straus and Giroux, 1998.

Kamberelis, George. 'Ingestion, Elimination, Sex, and Song: Trickster as Premodern Avatar of Postmodern Research Practice,' Qualitative Inquiry 9.5 (2003): 673-704.

Lindemann, Marilee. 'Who's Afraid of the Big Bad Witch? Queer Studies in American Literature.' American Literary History 12.4 (2000): 757-770.

Sedgwick, Eve Kosofsky. Epistemology of the Closet. Berkeley: California UP, 1990.

-. Novel Gazing: Queer Readings in Fiction. Durham and London: Duke UP, 1997.

—. Tendencies. Durham: Duke UP, 1993.

-, and Adam Frank, eds. Shame and Its Sisters: A Silvan Tomkins Reader. Durham: Duke UP, 1995.

Wilson, Elizabeth A. Affect and Artificial Intelligence. Seattle: U of Washington P, 2010 (forthcoming). 